\title{
Energy and Exergy Analysis of coupled Cycles utilizing new Generation Gas
}

\section{Turbines}

\section{Chang Cho ${ }^{\text {a* }}$}

${ }^{a}$ Department of Chemical Engineering, Faculty of Engineering, Shou University, Dashu, Taiwan

* Email: chcho19901990@gmail.com 


\begin{abstract}
The potential execution of optimized gas-steam combined cycles built around the latest generation gas turbine motors is analyzed, by implies of energy/exergy equalizations. The options here considered are the warm gas turbine and the H-series with closed-loop steam edge cooling.Recreations of execution were run employing a well-tested Modular Code created at the Office of Vitality Designing of Florence and subsequently improved to incorporate the calculation of exergy pulverization of all sorts (warm transfer, friction, blending, and chemical irreversibilities). The edge cooling process is analyzed in detail because it is recognized to be of capital significance for execution optimization. The distributions of the relative exergy devastation for the two solutions both competent of achieving energy/exergy efficiencies within the extend of 60 percent are compared and the potential for advancement is examined
\end{abstract}

Keywords: Energy; Exergy; Turbine; Efficiency 


\section{Introduction}

The foremost common vitality framework execution evaluation criteria are vitality based ("first law") and they are valuable for surveying the productivity of vitality utilize, and can be effortlessly changed over to vitality taken a toll efficiencies in the event that the costs of the vitality shapes of the valuable yields and paid inputs are known. Here we characterize as " "useful"' all vitality intuitive that have been utilized by the framework "owner', ordinarily in terms of money related esteem, and "paid" all vitality intelligent that have a coordinate fetched, as a rule money related, to the framework proprietor [1-3]. Hence, for illustration, the warm inputs that come from the environment for which the owner does not got to pay are not included. We hurry to include that investigations that address natural affect will incorporate trades with the environment as well $[4,5]$.

Since such energy-based criteria don't account for the quality of vitality, communicated as exergy, exergy-based criteria are moreover fitting as they account way better for utilize of vitality assets and allow much superior direction for framework advance ment [6]. They too can be changed over to exergy fetched efficiencies on the off chance that the exergy values of the valuable yields and paid inputs can be reasonably estimated [7]. Another set of criteria evaluate the contrast between the execution of a framework relative to an perfect one (reversible) that works between the same thermodynamic limits.

We should call these Second Law-based criteria, in spite of the fact that numerous creators utilize this term for exergy-based criteria. Eventually, choices on best plans are most regularly based on temperate contemplations, in which vitality (or exergy) are as it were one portion, and some of the time not the foremost noteworthy one, where the other parts incorporate capital venture, labor, insurance, taxes, etc [8]. It is 
additionally worth noticing that while performance criteria are most regularly connected to the complete framework, such as plant or vitality transformation gadget, they can be connected at any level, such as to distinctive components, inside spatial and transient forms, and down to the littlest molecule intuitive, when there's an intrigued in that kind of investigation $[9,10]$.

The appearance on the exergy market of gas/steam joined cycles with effectiveness surpassing 60 percent when powered with petroleum gas has suggested the genuine conversation starter of what is the real furthest reaches of productivity reachable by these exceptional vitality frameworks: significantly more significant is to comprehend if there is as yet an edge for thermodynamic enhancement inside these plants, or if further upgrades must be acquired by major innovative advances, (for example, water/steam shut circle cooling of turbine edges; hydrogen energizing with higher most extreme cycle temperature; expansion of fixing energy unit modules; and so forth.) As for every single new innovation, these means need significant use on examination and experimentation, and at the improvement stage offer lower unwavering quality, which is a significant worry to expected clients, who might regularly rather choose a develop innovation if this could arrive at comparable execution levels [11-13].

Regardless of whether the essential working information of the two motors were kept as close as conceivable to distributed information (blower stream rate, turbine delta temperature, coolant streams, and so on.), the chance of altering the weight proportion around the plan esteem was considered in the light of improving the coordinating with the steam bottoming cycle [14]. The model utilized for recreation is that created via Carcasci and Facchini, which has gone through exhaustive approval in numerous setups and for various gas turbine motors; an unmistakable component of this model is its completely verifiable nature, that is, there is 
no deterministic qualification among information and yield information however the model can work successfully gave any arrangement of predictable information [15].

This has permitted an agreeable expectation of execution in any event, when numerous fundamental information was absent from the producer; this component is additionally utilized for cross-checking the legitimacy of the distributed information and to recreate the genuine working information from estimated exhibitions. The model incorporates full treatment of cooling streams and the different assessment of the impacts of cutting edge cooling with a serious extent of detail. The particular code incorporates additionally the chance of shifting blower and turbine segments productivity just as cooling-wind stream as a component of weight proportion for off-plan investigation: for the current work, these highlights don't have significance, since an essentially thermodynamic examination was continued [16].

The blade cooling flowrate is just $\mathrm{T}_{\mathrm{Max}}$ subordinate (just changed in accordance with keeping up fixed metal temperatures) and doesn't have any effect on the blower pressure proportion, that is fixed at configuration working conditions. Clearly, all the working conditions and boundaries are tuned with the ones comparative with the considered machines in the current investigation thewith a full understanding of the working conditions. An ongoing expansion to the code has been the finished exergy balance, remembering assessment for all plant segments of the impacts of irreversibilities emerging from various sources, for example, heat transfer, friction, mixing of streams, chemical reactions, and interaction with the environment. The point by point exergy balance is utilized in this investigation to think about the presentation of plant segments and to comprehend the edges for potential execution improvement [17]. 


\section{Cycle with Reheat Gas Turbine}

The RHGT gas turbine cycle is portrayed schematically in Fig. 1. It would seem that a customary gas turbine cycle, aside from the subsequent ignition, acknowledged after the principal extension in the high weight turbine. The advancing proficiency pressure proportion is uprooted to moderately high qualities with warmth [18]. The act of warm presents some extra misfortunes regarding an equal straightforward cycle, that commonly lessen by about 0.5 rate focuses on the improvement in proficiency; fundamentally:

- a bigger weight drop is available with two ignition chambers;

- pressure misfortunes are additionally included by the diffuser, expected to permit the right fuel-gas streamlined conditions at the channel of the subsequent ignition chamber;

- the entire first turbine must be cooled in light of the high working temperature;

- the isentropic productivity of the entire pressure measure is diminished $\sim$ for equivalent degrees of polytropic proficiency! because of the higher streamlining pressure proportion regarding the basic cycle.

The principle working boundaries and results for the cycle with and without warm; this last is the worth augmenting power yield for the basic cycle! are summed up in Table 1. Expanding pressure proportion delivers a 3 percent improvement in productivity for the straightforward cycle, which is paid by a decrease in explicit work (15 percent); the act of warm permits improvement proficiency of about 2.5 percent, with a considerable recuperation in explicit work. Also, the warm cycle fumes gas temperature is sufficiently high to permit a profoundly proficient Heat Recovery Steam Generator (HRSG) [19]. 
Figure 2 shows the exergy decimation parity of the warm gas turbine cycle, contrasted and that of the basic cycle. This gainful impact is expected to preheating in the second burning the oxidant stream enters the ignition chamber at $1200 \mathrm{~K}$. So as to arrive at tantamount estimations of productivity and explicit work without warm, the terminating temperature ought to be raised to $1700 \mathrm{~K}$, with huge downsides as far as speculation and support costs. Warm appears hence to be a viable method to improve the thermodynamic exhibition of gas turbine cycles staying away from significant advancement issues [20].

A fascinating element of the warm cycle is the chance of changing the fumes gas temperature by fluctuating the warm weight level: this can be valuable to improve coupling with the bottoming cycle. Figure 3 shows the conduct of the fundamental exhibition boundaries as an element of warm weight; great execution can be accomplished at 16 bars, which speaks to a decent trade-off between explicit work and proficiency. Warm weight esteem enhancing explicit work (14 bars) was found. For each case, the cooling stream to the warm turbine segment was changed in accordance with keep up the right estimations of metal temperature. With estimations of warm weight in the scope of 14 to 16 bars, be that as it may, the fumes gas temperature is too low to even consider obtaining great execution from the bottoming cycle. The warm weight level ought to be let down to 11 bars; thusly, the productivity of clincher cycle is punished, however a predictable warmth recuperation happens in the joined cycle.

\section{H-Technology Cycle}

The helpful impacts of raising the greatest cycle temperature TMax are notable. Current age edge cooling procedures permit a distinction among $\mathrm{T}_{\mathrm{Max}}$ and $\mathrm{T}_{\mathrm{IT}}$ of about $150^{\circ} \mathrm{C}$ : this implies, if a high 
estimation of $\mathrm{T}_{\text {IT }}$ is thought of, a $\mathrm{T}_{\text {Max }}$ of at any rate $1850 \mathrm{~K}$ ought to be reached in the ignition chamber. Such high qualities include astounding issues for cooling the burning chamber dividers and the primary spout cutting edges. The $\mathrm{H}$-age gas turbine, working essentially with consolidated cycle arrangement and shut circle water/steam spout cooling, can unequivocally restrict with apparent points of interest as far as execution and NOx emanations [21]. An improved schematic of a steam cooled gas turbine cycle is spoken to in Fig. 4. The GT cycle is firmly combined with a bottoming steam cycle, both at the HRSG and inside the gas turbine, where warmth is taken out from the hot burning gas stream and moved to superheated halfway weight steam. The steam leaving the HP turbine is subsequently part into two streams: one is coordinated to the cooling arrangement of the gas turbine, the other to the warm segment of the HRSG. The two streams are remixed at the IP steam turbine delta. Steam is a proficient warmth move liquid, so a restricted sum is needed to cool the turbine. Thusly, additionally a restricted measure of air must be seeped at blower release for edge cooling. The part level exergy devastation offset is delineated concerning a gas turbine, and contrasted and that of past age machines. The burning chamber shows moderately low estimations of exergy pulverization in the H-design as for normally experienced qualities; a comparative presentation is accomplished by the G-motor, which anyway includes higher estimations of $\mathrm{T}_{\operatorname{Max}}(\mathrm{K})$. For every one of the three cases, $\mathrm{T}_{\mathrm{IT}}$ was fixed at a similar level and afterward $\mathrm{T}_{\text {Max }}$ determined: since the $\mathrm{H}$-arrangement is steam cooled, a temperature drop between the first stator and the first rotor of just $60-70^{\circ} \mathrm{C}$ happens, while for the G-arrangement this drop is around $150-180^{\circ} \mathrm{C}$. Thus, TMax is higher and the related burning chamber exergy annihilation somewhat lower for the $\mathrm{G}$ one. 


\section{The HRSG and Bottoming Cycle}

A schematic of the HRSG and bottoming cycle is appeared in Fig. 6. The three-pressure-level warmth recuperation steam generator was reproduced utilizing similar estimations of the essential thermodynamic boundaries for the plants. The qualities are not actually those advancing the exhibition of every one of the two reference plants, which are anyway generally close as the GT exhaust temperature level is very comparative. Choosing similar qualities for the two cases permits a simpler examination between the two arrangements. On the off chance that the bottomer and HRSG areas were changed, the exhibition of the consolidated cycle would not change vigorously (until the bottomer conditions permit to work at a similar temperature and weight levels) on the grounds that comparable vaues of the gas turbine fumes temperature were found.

\section{Exergy Analysis of the Combined Cycles}

The outcomes from now on introduced remember for worldwide terms the impacts of turbine cooling; subtleties of exergy bookkeeping in cooled extensions are given in an ensuing passage. Concerning the consolidated cycle, the decision of a warm setup permits the increase of around 2 to 3 rate focuses in exergy proficiency as for traditional air-cooled gas turbine burning cycles, under comparative states of $\mathrm{T}_{\mathrm{Max}}$. The decrease in burning irreversibility permits the plant dependent on the warm alternative to arrive at fascinating figures for exergy effectiveness even with restricted $\mathrm{T}_{\text {IT }}$ esteems, and with a thermomechanical stacking which is lower than that of numerous air subordinate or even mechanical gas turbines. Some different misfortunes, the aircooled turbine development, which is talked about in detail independently! are generally huge as for what could be reachable with further developed innovations. Nonetheless, an incomplete recuperation happens at joined cycle level, in light of the fact that the warm permits the choice of high GT pressure proportions yet keeping up generally high depletes temperature, which are 
advantageous for the HRSG execution. The H-innovation joined cycle power plant includes a superior exergy proficiency, which mirrors the high estimation of warm productivity. Information for current-age air-cooled renditions of a similar motor are additionally appeared. The high proficiency is an aftereffect of the accompanying three fundamental highlights: The most extreme cycle temperature is high, which permits restricting the ignition irreversibility to values even lower than that of the warm gas turbine. While considering the air-cooled forms of this motor, the burning exergy misfortune was assessed separately at 29.8 percent for the MS 9001-FA and 26.6 percent for the MS 9001- . The steam cooling permits accomplishment of generally excellent efficiencies in any event, for high-temperature, cooled turbine stages, in examination with traditional gas turbines. Steam cooling is regenerative, and this is reflected in the little exergy demolition in the warmth move cycle of the HRSG reheater, whose rating and size are diminished as an important flowrate of warmed steam results from the cooling stream of the gas turbine sharp edges. 


\section{Conclusions}

The examination of reproduced results (thermodynamic investigation) demonstrates that both $\mathrm{H}$ innovation and warm lead to an important increment of execution regarding explicit work and effectiveness . An advantageous reproduction indicated that the mix of the two innovations could prompt a productivity of around 62 percent at the present mechanical level Power plants dependent on a H-innovation gas turbine have potential for accomplishing proficiency levels which are by and by past the constraints of ordinarily cooled gas turbine plants; notwithstanding, this decision involves predictable innovative issues which will absolutely be reflected in the higher plant speculation expenses, and some level of vulnerability about dependability in any event for the principal plants fabricated. Then again, the GT24 utilizes solidified innovation with lower venture consumption, yet in addition a lower execution potential. The chance of the use of the H-innovation is carefully subject to the breakdown of the money related interest regarding buy and activity of the plant. 


\section{Reference}

[1] Aoki, S., Uematsu, K., Suenaga, K., Mori, H., and Sugishita, H., 1998, “'A Study of Hydrogen Combustion Turbines,"’ ASME Paper 98-GT-394.

[2] Carcasci, C., and Facchini, B., 1995, “A Numerical Method For Power Simulations," presented at the GTI TURBO Expo Houston 1995.

[3] El Masri, M. A., 1997, “Exergy Balance Analysis of the Reheat Gas Turbine Combined Cycle," presented at the 2nd ASME-JSME Thermal Engineering Conference, Honolulu, Hawaii.

[4] Kawaike, K., et al., 1984, "Effect of New Blade Cooling System with Minimized Gas Temperature Diluition on Gas Turbine Performance,'” ASME Paper 84-GT-89.

[5] Koellen, O., and Koschel, W., 1986, “Effect of Film Cooling on the Aerodynamic Performance of a Turbine Cascade," Heat Transfer and Cooling in Gas Turbine, AGARD Rep

[6] Ghalandari, V., Majd, M.M. and Golestanian, A., 2019. Energy audit for pyro-processing unit of a new generation cement plant and feasibility study for recovering waste heat: A case study. Energy, 173, 833-843.

[7] Ghalandari, V. and Iranmanesh, A., 2020. Energy and exergy analyses for a cement ball mill of a new generation cement plant and optimizing grinding process: A case study. Advanced Powder Technology.

[8] Hepbasli, A. and Akdemir, O., 2004. Energy and exergy analysis of a ground source (geothermal) heat pump system. Energy conversion and management, 45, 737-753.

[9] Katsioti, M., Tsakiridis, P.E., Giannatos, P., Tsibouki, Z. and Marinos, J., 2009. Characterization of various cement grinding aids and their impact on grindability and cement performance. Construction and Building Materials, 23, 1954-1959. 
[10] Kotas, T.J., 1985. The Exergy Method of Thermal Plant Analysis, Anchor Brendon Ltd. Tiptree, Essex.

[11] Kong, L., Price, L., Hasanbeigi, A., Liu, H. and Li, J., 2013. Potential for reducing paper mill energy use and carbon dioxide emissions through plant-wide energy audits: A case study in China. Applied Energy, 102, 1334-1342.

[12] Li, L., Wang, J., Tan, Z., Ge, X., Zhang, J. and Yun, X., 2014. Policies for eliminating lowefficiency production capacities and improving energy efficiency of energy-intensive industries in China. Renewable and sustainable energy reviews, 39, 312-326.

[13] Li Z.F., Sumathy K. (2001). Simulation of a solar absorption air conditioning system, Energy Conversion and Management, Vol. 42, No. 3, pp. 313-327.

[14] Li Z.F., Sumathy K. (2001). Experimental studies on a solar powered air conditioning system with partitioned hot water storage tank, Solar Energy, Vol. 71, No. 5, pp. 285-297.

[15] Atmaca I., Yigit A. (2003). Simulation of solarpowered absorption cooling system, Renewable Energy, Vol. 28, No. 8, pp. 1277-1293.

[16] Sayegh M.A. (2007). The solar contribution to air conditioning systems for residential buildings, Desalination, Vol. 29, pp. 171-176.

[17] Talbi M.M., Agnew B. (2000). Exergy analysis: an absorption refrigerator using lithium bromide and water as the working fluids, Applied Thermal Engineering, Vol. 20, pp. 619-630.

[18] Şencan A., Yakut K.A., Soteris A. (2005). Exergy analysis of lithium bromide/water absorption systems, Renewable Energy, Vol. 30, pp. 645- 657.

[19] Infante Ferreira C.A., Kim D.S. (2014). Technoeconomic review of solar cooling technologies based on location-specific data, Int. J. Refrig., Vol. 39, pp. 23-27. 
[20] Sayadi Z., Thameur N.B., Bourouis M., Bellagi A. (2013). Performance optimization of solar driven small-cooled absorption-diffusion chiller working with light hydrocarbons, Energy Conversion and Management, Vol. 74, pp. 299-307.

[21] Falahatkar A., Akhavan H. (2014). Design and simulation of a single effect $\mathrm{LiBr}-\mathrm{H} 2 \mathrm{O}$ absorption chiller for a building in Tehran, Energy Journal of Iran, Vol. 14, pp. 37-46. 


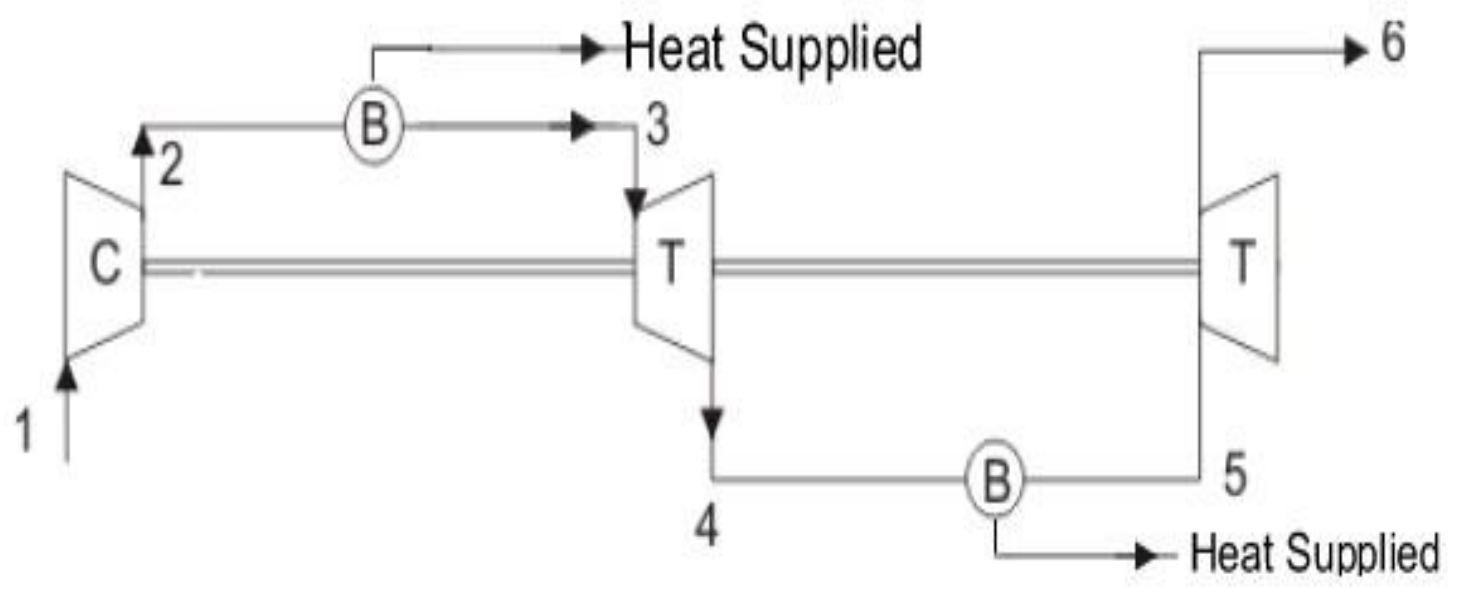

Fig 1. Reheat cycle gas turbine plant 


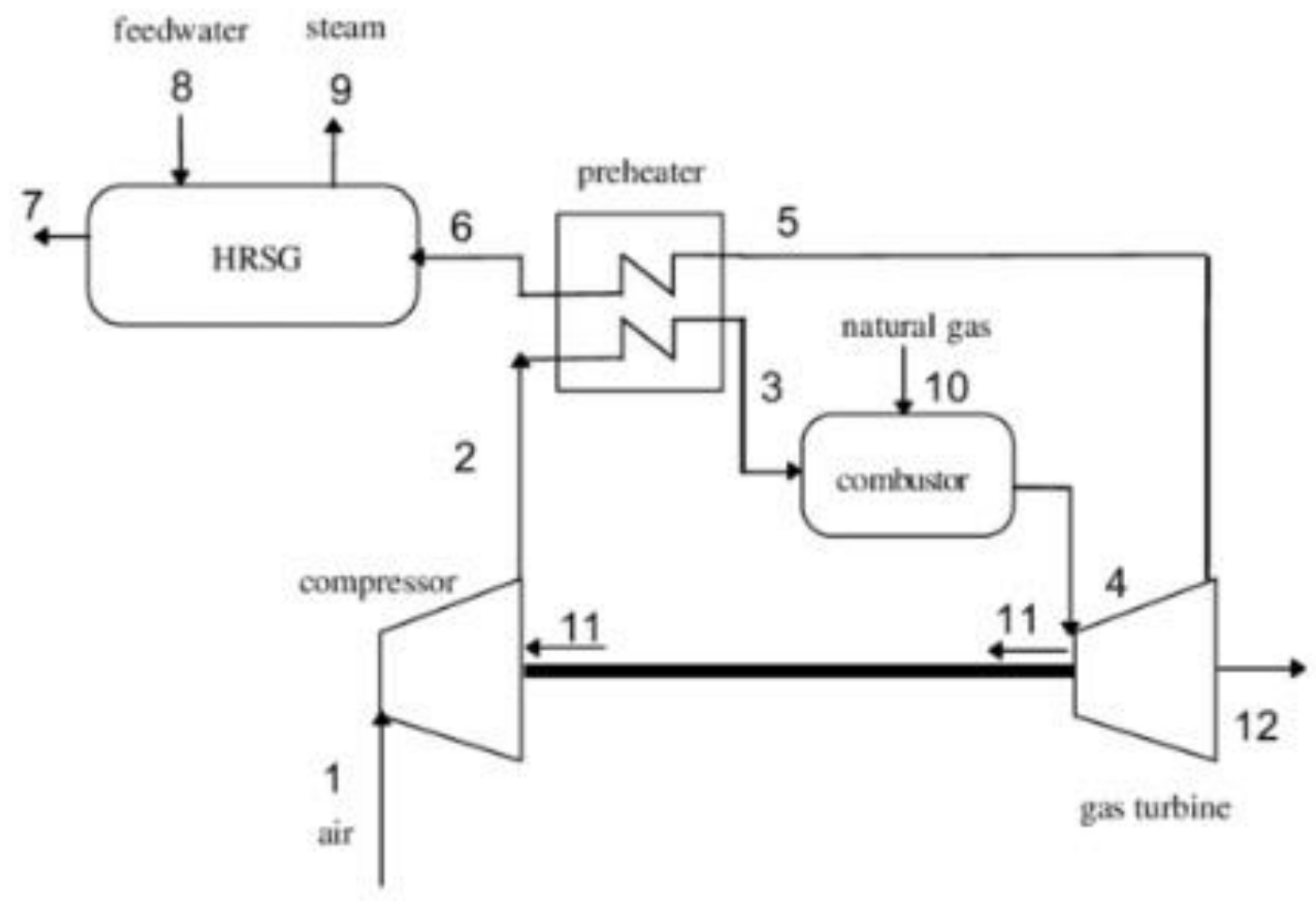

Fig 2. Schematic of the heat recovery steam generator 


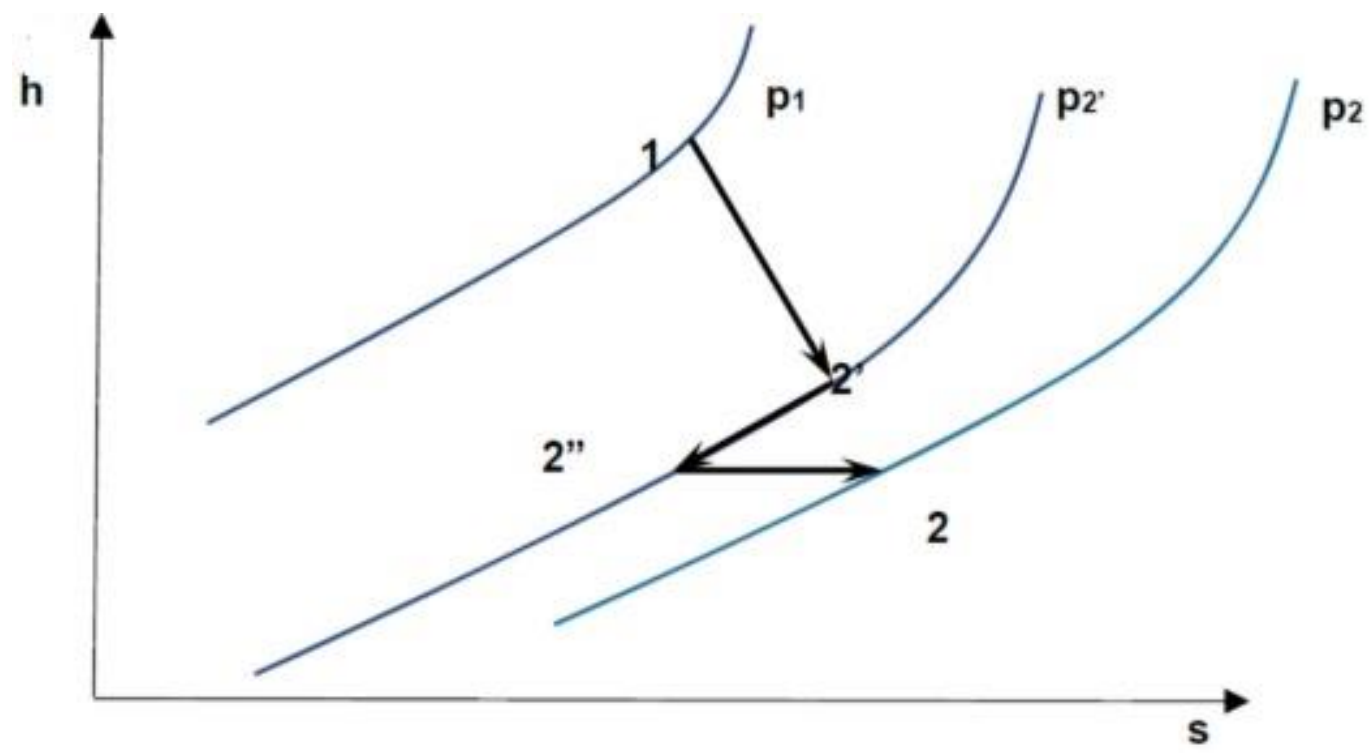

Fig 3. A gas turbine cooled-stage expansion 